\title{
Editorial: Composite Use of High Strength Steel and Concrete Materials for Sustainable Civil Engineering
}

\author{
Ming-Xiang Xiong ${ }^{1 *}$, Yanbo Wang $^{2}$, Xuemei Liu $^{3 *}$ and Guangming Chen ${ }^{4}$ \\ ${ }^{1}$ Protective Structures Center, School of Civil Engineering, Guangzhou University, Guangzhou, China, ${ }^{2}$ College of Civil \\ Engineering, Tongji University, Shanghai, China, ${ }^{3}$ Department of Infrastructure Engineering, The University of Melbourne, Parkville, \\ VIC, Australia, ${ }^{4}$ State Key Laboratory of Subtropical Building Science, South China University of Technology, Guangzhou, China
}

Keywords: high strength, ultra-high strength steel, recycled aggregate concrete, prefabrication, composite members

\section{Editorial on the Research Article}

Composite Use of High Strength Steel and Concrete Materials for Sustainable Civil Engineering

The need for sustainable construction has been accelerated worldwide in order to reduce the use of construction materials and labor costs. High strength materials represent one option for addressing this need, as the higher the strength, the smaller the member size required. This will free up more usable floor area and require fewer materials and less construction work.

The composite use of high strength materials is a potential way of achieving more sustainable construction. To bridge the gap between theoretical development and practical application, the guest editorial team organized this Frontiers in Materials: Structural Materials Research Topic on "Composite Use of High Strength Steel and Concrete Materials for Sustainable Civil Engineering." The main objective is to present a scientifically and technically rigorous approach to the composite use of high strength materials, understand their mechanical behaviors, and facilitate engineering applications. This Research Topic contains eight contributions ranging from the

OPEN ACCESS

Edited and reviewed by: John L. Provis,

The University of Sheffield, United Kingdom

*Correspondence: Ming-Xiang Xiong

cvexmx@gzhu.edu.cn

Xuemei Liu

xuemei.liu@unimelb.edu.au

Received: 11 June 2021

Accepted: 28 June 2021

Published: 19 August 2021

Citation:

Xiong M-X, Wang Y, Liu X and Chen G (2021) Editorial: Composite Use of High Strength Steel and Concrete Materials for Sustainable Civil Engineering.

Front. Mater. 8:723587. doi: 10.3389/fmats.2021.723587 composite strength of reinforced soft clay and innovative use of ultrahigh strength steel, through the structural problem of capacity enhancement for steel-concrete composite members, to the analysis and design of recycled aggregate concrete (RAC) characterized load-carrying members. Experimental studies, numerical modeling, and structural design are all important aspects of the Research Topic.

We first illustrate the overall picture by considering the paper by Zheng and Wu. This study explores the early strength development of soft clay by combining it with ground granulated blast furnace slag (GGBFS) and fly ash (FA) based geopolymer. The results demonstrated the contribution of prolific hydration products to strengthen soft clay and, more importantly, opened new possibilities for the reinforcement of soft clay by replacing ordinary Portland cement with the GGBFS-FA based geopolymers. A different perspective from Peng et al. has been focused on the dynamic strength of G50 ultra-high-strength steel plates struck by tungsten alloy spherical fragments at high velocity; a different failure model from low strength steel plates was found, which provides clear evidence that the tungsten fragment is eroded, sharpened and breaks into pieces during the penetration process.

To further enhance the load-carrying capacity of steel-concrete composite members, Chen et al. introduced a design scheme to reinforce concrete filled square steel tubular (CFST) columns with inclined square stirrups, and a significant improvement of up to $21 \%$ in the load-carrying capacity has been found from such reinforcement. In addition, the ductility is improved and the adverse "arch effect" is reduced. In practice, concrete is sometimes under-reinforced by steel tubes, which may cause premature failure in the CFST columns. To know more about their mechanical behavior, an 
experimental study by Lu et al. developed a practical calculation method for the load carrying capacity of the CFST columns under compression.

As mentioned above, reduced labor costs also contribute to the sustainability of construction. For this, the structural members may be partially prefabricated in a factory and then installed in situ. The mechanical performance of the prefabricated members could be very different from that of those cast in situ. To ascertain such differences, Wang et al. investigated the shear behavior of multi-bolt connectors for prefabricated steel-concrete composite beams through finite element analysis. A design formula was then proposed to predict the shear resistance of the bolt by considering the multibolt effect in the parametric analysis. The use of construction and demolition waste as aggregates to produce RAC has been considered an effective way to address environmental issues in the construction section. However, the strength and modulus of RAC are usually lower than those of concrete using natural aggregates, and so to use RAC in a highstrength way, researchers have attempted to confine it in a steel tube to form the composite column, since the confinement can significantly improve its strength. Among those works, Liu et al. numerically studied the compressive behavior of RAC filled steel tubular (RACFST) columns by looking into the effect and efficiency of confinement. The effect and efficiency are slightly weaker than counterparts that use natural aggregates; however, a study by Xu et al. revealed that RACFST columns could achieve comparable seismic performance when compared to conventional CFST columns. Furthermore, the bond behavior between RAC and steel subject to a cyclic scheme of high temperature and water cooling was investigated by Zhou et al., who found that the high temperature and the cooling process deteriorated the bond strength, which has an adverse influence on the ultimate load-carrying capacity of the composite members.

The diverse nature of the contributions in this collection is a testament to cross-disciplinary research activities about the composite use of high-strength materials. Nevertheless, there is a common thread running through all contributions, which all observe that high strength, when properly achieved, can be a source of great creativity in achieving more sustainable construction.

\section{AUTHOR CONTRIBUTIONS}

All authors listed have made a substantial, direct, and intellectual contribution to the work and approved it for publication.

Conflict of Interest: The authors declare that the research was conducted in the absence of any commercial or financial relationships that could be construed as a potential conflict of interest.

Publisher's Note: All claims expressed in this article are solely those of the authors and do not necessarily represent those of their affiliated organizations, or those of the publisher, the editors and the reviewers. Any product that may be evaluated in this article, or claim that may be made by its manufacturer, is not guaranteed or endorsed by the publisher.

Copyright (๑) 2021 Xiong, Wang, Liu and Chen. This is an open-access article distributed under the terms of the Creative Commons Attribution License (CC BY). The use, distribution or reproduction in other forums is permitted, provided the original author(s) and the copyright owner(s) are credited and that the original publication in this journal is cited, in accordance with accepted academic practice. No use, distribution or reproduction is permitted which does not comply with these terms. 